\title{
Importancia de la investigación
}

Importance of research

\author{
Arlen Cerón Islas ${ }^{a}$, Heidy Cerón Islas ${ }^{b}$, Reyna Joselin Rodríguez Reyes ${ }^{c}$
}

\begin{abstract}
:
To investigate is to research for temporal truths in order to generate new knowledge that will allow us to expand borders and discover the facts in an orderly and systematic way.

The importance of research is to answer rare questions with scientific searches; this questions originate from deliberate inquiries that involve and require organization through a process that contains methods and techniques called the scientific method.

Once the true answer has been found, it becomes necessary to communicate the findings and share the answers found to expand the frontiers of knowledge; this is because the solutions that have resulted depend on the place and time (spatial and temporal) and the purpose of the problem to be solved, that is, they are circumstantial.

When starting an investigation, it is necessary to consider that in order to solve the problem to be investigated, it is essential to determine the object (issue, topic or situation); the objective of the objective (what you want to achieve) and the reasons for the question (guide); this is define the inquiry process that is summarized in 6 steps: choose the topic of interest, justify why, gather material (sources of information), define methodology (experiment), capture the work and carry out a final review.
\end{abstract}

Keywords:

Knowledge, research, method

\section{Resumen:}

Investigar es realizar la búsqueda de verdades temporales con la finalidad de generar nuevos conocimientos que permitan ampliar fronteras y descubrir de forma ordenada y sistemática los hechos.

La importancia de la investigación es dar respuesta a preguntas poco comunes con búsquedas científicas; dichas preguntas se originan de indagaciones deliberadas que implican y requieren de organización a través de un proceso que contiene métodos y técnicas denominado método científico.

Una vez encontrada la respuesta verdadera se vuelve necesario comunicar los hallazgos y compartir las respuestas encontradas que permitan ampliar las fronteras del conocimiento; lo anterior debido a que las soluciones que han resultado dependen del lugar y tiempo (espacial y temporal) y de la finalidad del problema a resolver, es decir, son circunstanciales.

Al iniciar una investigación es necesario considerar que para poder resolver la problemática a investigar es fundamental determinar el objeto (asunto, tema o situación); el objetivo del objetivo (lo que desea lograr) y los motivos que origina la pregunta (guía); a saber, definir el proceso de indagación que se resume en 6 pasos: escoger el tema de interés, justificar el por qué, reunir material (fuentes de información), definir metodología (experimentar), plasmar el trabajo y realizar revisión final.

\section{Palabras Clave:}

Conocimiento, investigación, método 


\section{Referencias}

[1] Vital Carrillo, M.. La investigación en los procesos de enseñanza aprendizaje. Boletín científico de la Escuela Preparatoria No. 4. México; 2015. 3 (6). Recuperado de https://www.uaeh.edu.mx/scige/boletin/prepa4/n6/e4.html\#refe1

[2] Llórens Baéz, L. [CEAD UABC]. Qué es y para qué sirve hacer investigación [Archivo de video]. 2016. Recuperado de https://www.youtube.com/watch?v=jxnaQBg-48g

[3] Compartir palabra maestra. [\#PalabraMaestra]. ¿Que es investigar? [Archivo de video]. 2019. Recuperado de https://www.youtube.com/watch?v=nIDVCt3F_-M

[4] RAE.. Diccionario de la lengua española. 2019. Recuperado en https://dle.rae.es/investigar

[5] Hernández Sampieri, R., Fernández, C. y Baptista, L. Metodología de la investigación. McGrawHill Education. México; 2014. Sexta edición. México

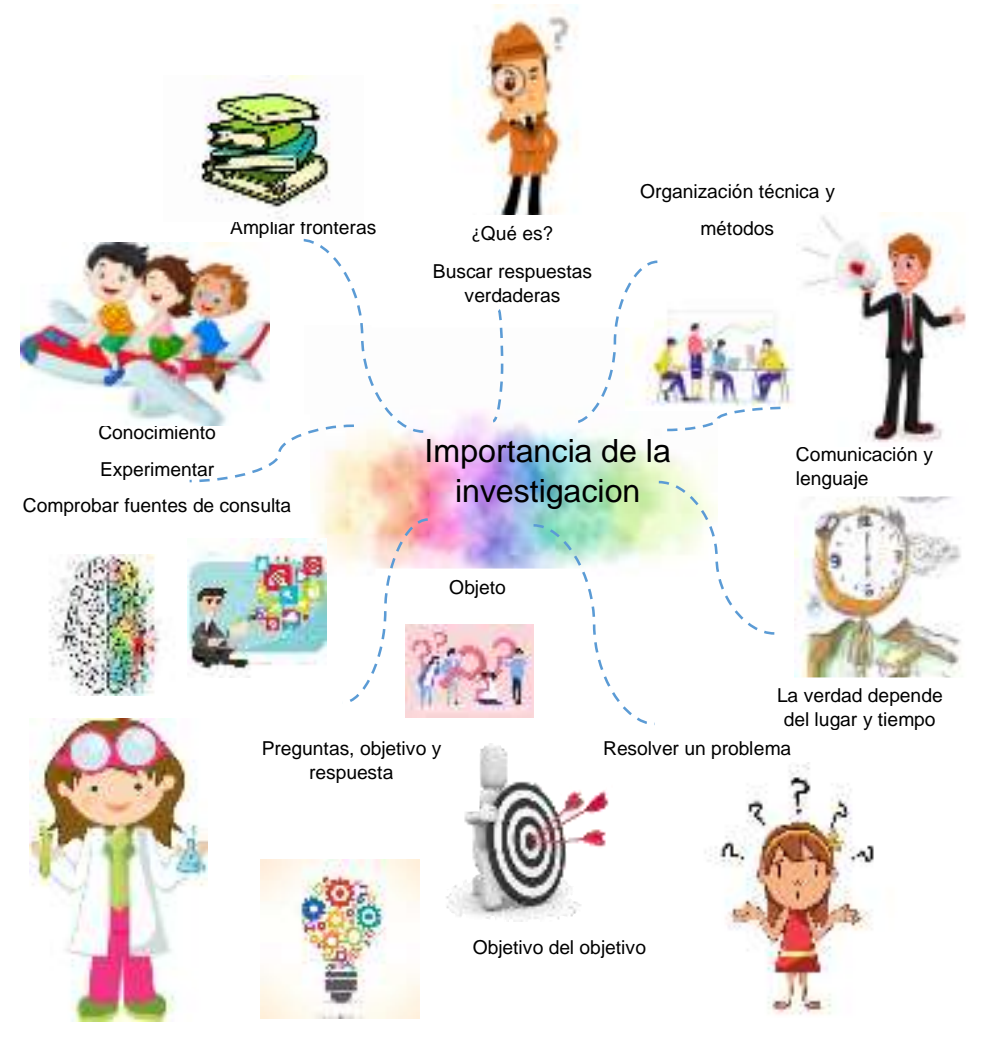

Figura 1. Importancia de la investigación

Fuente elaboración propia, 2020. 